\title{
Erratum to: Treatment of elastase-induced intracranial aneurysms in New Zealand white rabbits by use of a novel neurovascular embolization stent device
}

\author{
Anna Luisa Kühn • Christian Roth • Bernd Romeike • \\ Iris Quasar Grunwald
}

Published online: 11 January 2014

(C) Springer-Verlag Berlin Heidelberg 2014

\section{Erratum to: Neuroradiology}

DOI 10.1007/s00234-009-0605-9

Print publication of this paper was delayed because not all listed authors approved the final version of the paper when it was submitted. The statement "Kühn and Roth contributed equally" means that both authors have to be considered as first authors. Finally, the original author statement "We declare that we have no conflict of interest" is false since the stents implanted in the study were supplied for free by Nfocus Neuromedical, Inc.

The online version of the original article can be found at http://dx.doi.org/ 10.1007/s00234-009-0605-9.

A. L. Kühn · C. Roth

Department for Interventional and Diagnostic Neuroradiology,

Saarland University, Saarland, Germany

B. Romeike

Department of Neuropathology, Jena University, Jena, Germany

I. Q. Grunwald $(\bowtie)$

Acute Vascular Imaging Centre, Level 2, Biomedical Research

Centre, John Radcliffe Hospital, Oxford OX3 9DU, UK

e-mail: i.grunwald@web.de 